Journal of Health Science
(Jurnal Ilmu Kesehatan)
$\frac{\text { https://www.ejournalwiraraja.com/index.php/JIK }}{2356-5284 \text { (Print) } 12356-5543 \text { (online) }}$

\title{
Pengaruh Akupresur Terhadap Pengurangan Nyeri Kepala pada Ibu Hamil Trimester 1 di Tempat Praktek Mandiri Bidan Muarofah Surabaya
}

\author{
Eka Meiri Kurniyati ${ }^{1}$, Arisda Candra Satriawati ${ }^{2}$, Hadina Eka Camila ${ }^{3}$ \\ ${ }^{1}$ Program Studi Sarjana Kebidanan Universitas Wiraraja Madura \\ ${ }^{2,3}$ Program Studi Profesi Kebidanan Universitas Wiraraja Madura \\ 1ekameiri87@gmail.com*,2arisdacandra@gmail.com, hadinaeka.fik@wiraraja.ac.id \\ *Corresponding author
}

\begin{tabular}{ll}
\hline Informasi artikel & ABSTRAK \\
\hline Sejarah artikel: & Mayoritas ibu hamil mengalami sakit kepala pada trimester pertama dan hal \\
Received: 16-042020 & ini menjadi penyebab dari kecemasan dan ketidaknyamanan para ibu saat \\
Revised: 25-05-2020 & hamil muda. Tujuan dalam penelitian ini adalah untuk mengetahui \\
Accepted:30-05-2020 & Pengaruh Teknik Akupresur terhadap pengurangan rasa sakit kepala pada \\
& ibu hamil trimester pertama di PMB Muarofah A.Md Keb. Ini merupakan \\
& penelitian pra eksperimental dengan pendekatan one group pre test - post \\
Kata kunci: & test. Populasi dan sampel pada penelitian ini adalah semua ibu hamil \\
Sakit kepala & trimester pertama yang mengalami sakit kepala sebanyak 20 orang. Teknik \\
Akupresur & sampling menggunakan accidental sampling. Pengumpulan data dengan \\
Ibu hamil & lembar observasi, Analisa data menggunakan uji T Berpasangan.Hasil \\
& penelitian menunjukkan bahwa distribusi responden berdasarkan nyeri \\
& sebelum intervensi sebagian besar nyeri sedang 16 responden (80\%) dan \\
& sebagian kecil nyeri ringan sebanyak 4 responden (20\%). Nyeri sesudah \\
& intervensi sebagian besar Nyeri ringan sebanyak 10 responden (50\%) dan \\
& sebagian kecil nyeri sedang sebanyak 1 responden (5.0\%). Hasil analisis \\
& P=0,000. Kesimpulan penelitian ini yaitu ada Pengaruh Tekhnik Akupresur \\
& Terhadap Pengurangan Rasa Sakit Kepala pada Ibu Hamil Trimester Pertama \\
& di PMB Muarofah A.Md Keb. Diharapkan bidan dapat menjadikan akupresur \\
& sebagai salah satu intervensi dalam menurunkan intensitas nyeri sakit \\
& kepala pada ibu hamil trimester pertama di pelayanan kesehatan.
\end{tabular}

Key word:

Headache

Acupressure

Woman pregnant

\begin{abstract}
The majority of pregnant women experience headaches in the first trimester and it is often the cause of the anxiety and discomfort of the mother while pregnant. The purpose of this study is to determine the effect of acupressure techniques to the reduction of headache pain in pregnant women in the first trimester PMB Muarofah A.Md Keb Surabaya.This study is a pre-experimental approach to one group pre test - post test. Population and sample in this study were all first trimester pregnant women with headache as many as 20 people. Sampling technique uses accidental sampling. Collecting data using observation sheets, Data analysis using Paired $T$ test. The results showed that the distribution of respondents by pain before intervention mostly moderate pain 16 respondents (80\%) and a small portion mild pain as much as 4 respondents (20\%). Pain after intervention mostly mild pain as much as 10 respondents (50\%) and a small percentage of moderate pain as much as one respondent (5.0\%). The results of the analysis of $P=0.000$ The conclusion of this research that there Acupressure Technique Effect Against Pain Reduction on Maternal Head First Trimester 1 in PMB Muarofah A.Md Keb in Surabaya. Expected midwives can make acupressure massage as one of the interventions in reducing headache pain intensity in the first trimester pregnant women in health.
\end{abstract}




\section{PENDAHULUAN}

Beberapa penelitian yang melibatkan survei terhadap wanita hamil menurut riskesdes tahun 2010 menunjukan bahwa sekitar $16 \%$ wanita hamil di trimester pertama mengalami sakit kepala. Diperkirakan bahwa 1 dari 5 pada wanita hamil mengalami cephalgia. Hasil survey menunjukkan bahwa $17 \%$ wanita hamil mengalami migrain di trimester pertama kehamilannya. Diduga bahwa penyebab dari migrain pada ibu hamil karena meningkatnya aliran darah ke otak.

Cephalgia yang dialami ibu hamil di trimester pertama disebabkan terdapat peningkatan aliran darah ke tubuh. Ketika ibu hamil dalam keadaan duduk, kemudian berbaring dan sebaliknya, system sirkulasi darah sulit berdaptasi pada keadaan ini sehingga menyebabkan cephalgia. Sakit kepala atau pusing yang lebih sering dari biasanya dapat disebabkan oleh faktor fisik maupun emosional. Faktor lain yang dapat menyebabkan cephalgia adalah pola makan yang tidak teratur, perasaan tegang dan depresi.

Penatalaksanaan cephalgia pada ibu hamil trimester pertama dapat secara farmakologi dan non farmakologi. Penanganan pada non farmakologi antara lain dengan akupresur, relaksasai, imajinasi terbimbing, akupuntur dan psikoterapi. (Sulistyoningrum, 2017). Akupresur (pemijatan) merupakan teknik penanganan penyakit dengan memijat bagian tubuh tertentu untuk mengaktifkan peredaran energi vital qi. Akupresur juga disebut dengan akupuntur tanpa jarum karena tekniknya menekan titik-titik tertentu menggunakan jari tangan .(Jayanti \& Mayasari; Pravikasari, 2014). Tugas seorang bidan dalam menangani cephalgia pada ibu hamil trimester pertama adalah dengan mampu mengurangi nyeri cepahlgia baik ssecara farmakologi maupun non farmakologi sehingga ibu dapat melewati masa ini. (Hasanah, 2014)

\section{METODE PENELITIAN}

Penelitian ini adalah penelitian pra eksperimental dengan rancang bangun one group pre test- post test yaitu melibatkan satu kelompok subjek dengan cara membandingkan hasil pre test dengan post test. Kelompok subjek di ukur kemudian ditulis pada lembar observasi sebelum dilakukan intervensi, kemudian di observasi lagi setelah diberikan intervensi. Penelitian ini tidak melibatkan kelompok kontrol, karena sudah dilakukan observasi awal (pre test) sehingga peneliti menganalisis memungkinkan perubahan-perubahan yang terjadi setelah diberikan intervensi. Instrumen pada penelitian ini menggunakan penilaian intensitas nyeri dengan skala numeric. Penilaian skala numeric menggunakan skala dari angka 0-10. Populasi penelitian ini adalah semua ibu hamil trimester pertama di PMB Muarofah A.Md Keb Surabaya pada Januari 2020 sejumlah 30 orang. Teknik sampling menggunakan accindental sampling dengan jumlah sampel 28 orang. analisa datanya menggunakan uji Wilcoxon

\section{A. DATA UMUM}

\section{Distribusi Frekuensi Responden} Berdasarkan Umur.

Distribusi Frekuensi Responden Berdasarkan Umur di PMB Muarofah

\begin{tabular}{cccc}
\hline No & Umur (tahun) & $\mathbf{F}$ & $\mathbf{( \% )}$ \\
\hline $\mathbf{1}$ & $<30$ & 15 & 75 \\
\hline $\mathbf{2}$ & 30 & 2 & 10 \\
\hline $\mathbf{3}$ & $>30$ & 3 & 15 \\
\hline & Total & 20 & 100 \\
\hline
\end{tabular}

Sumber: Data Primer, 2020

Tabel diatas menunjukkan bahwa sebagaian besar responden umur <30 sebanyak (75\%), dan sebagian kecil berumur 30 tahun (10\%).

\begin{tabular}{cccc}
2 & $\begin{array}{c}\text { 2. Distribusi } \\
\text { Berdasarkan Pendidikan }\end{array}$ & $\begin{array}{c}\text { Frekuensi } \\
\text { Responden }\end{array}$ \\
\hline No & Pendidikan & F & \% \\
\hline $\mathbf{1}$ & SD & 5 & 25 \\
\hline $\mathbf{2}$ & SMP & 9 & 45 \\
\hline $\mathbf{3}$ & SMA & 6 & 30 \\
\hline & Total & 20 & 100
\end{tabular}

Sumber : Data Primer, 2020

Hasil distribusi responden berdasarkan pendidikan sebagian besar pendidikannya adalah SMP sebanyak 9 responden (45\%) dan sebagian kecil pendidikan SD sebanyak 2 responden (25\%).

\section{Distribusi Frekuensi Responden Berdasarkan Paritas}

Distribusi frekuensi responden berdasarkan paritas di PMB Muarofah bulan Januari 2020

\begin{tabular}{clcc}
\hline No & Paritas & F & (\%) \\
\hline $\mathbf{1}$ & Primipara & 4 & 20 \\
\hline $\mathbf{2}$ & Multipara & 6 & 30 \\
\hline $\mathbf{3}$ & $\begin{array}{l}\text { Grande } \\
\text { Multipara }\end{array}$ & 10 & 50 \\
\hline & Jumlah & 20 & 100
\end{tabular}

Sumber : Data Primer, 2020 
Berdasarkan tabel diatas menunjukkan bahwa distribusi responden berdasarkan paritas sebagian besar grande multipara sebanyak 10 responden (50\%) dan sebagian kecil primipara sebanyak 4 responden (20\%).

\section{Distribusi Frekuensi Responden Berdasarkan Tekanan Darah}

Distribusi Frekuensi Responden Berdasarkan Tekanan Darah di PMB Muarofah Bulan Januari 2020

\begin{tabular}{cccc}
\hline No & Tekanan Darah & F & (\%) \\
\hline $\mathbf{1}$ & Normal & 19 & 95 \\
\hline $\mathbf{2}$ & Rendah & 1 & 5 \\
\hline $\mathbf{3}$ & Tinggi & 0 & 0 \\
\hline & Total & 20 & 100 \\
\hline
\end{tabular}

\section{B. DATA KHUSUS}

1. Nyeri Sebelum Pemberian Akupresure Distribusi Frekuensi Responden Berdasarkan nyeri sebelum pemberian akupresur di PMB Muarofah

\begin{tabular}{cccc}
\hline No & Tingkat Nyeri & $\mathbf{F}$ & $\mathbf{\%}$ \\
\hline $\mathbf{1}$ & Tidak Nyeri & 0 & 0 \\
\hline $\mathbf{2}$ & Nyeri Ringan & 4 & 20 \\
\hline $\mathbf{3}$ & Nyeri Sedang & 16 & 80 \\
\hline & Total & 20 & 100
\end{tabular}

\section{Sumber Januari 2020}

Berdasarkan tabel diatas menunjukkan bahwa distribusi responden berdasarkan nyeri sebelum di intervensi sebagian besar nyeri sedang 16 responden (80\%) dan sebagian kecil nyeri ringan sebanyak 4 responden (20\%).

\section{Nyeri Sesudah Pemberian Akupresur}

Distribusi frekuensi responden berdasarkan nyeri sesudah pemberian akupresur di BPM Muarofah A.Md Keb

\begin{tabular}{cccc}
\hline No & Tingkat Nyeri & $\mathbf{F}$ & $\mathbf{\%}$ \\
\hline $\mathbf{1}$ & Tidak Nyeri & 9 & 45 \\
\hline $\mathbf{2}$ & Nyeri Ringan & 10 & 50 \\
\hline $\mathbf{3}$ & Nyeri Sedang & 1 & 5 \\
\hline & Total & 20 & 100
\end{tabular}

Sumber : Data Primer, 2020

Hasil distribusi frekuen si intensitas nyeri setelah dilakukan pemijatan menunjukkan bahwa sebagian besar ibu hamil merasakan nyeri ringan sebanyak 10 responden (50\%) dan sebagian kecil nyeri sedang sebanyak 1 responden (5.0\%).
3. Pengaruh Akupresur terhadap pengurangan rasa sakit kepala pada ibu hamil trimester pertama

Hasil Analisis Statistik dengan Uji Wilcoxon

\begin{tabular}{lccc}
\hline Kategori & N & Rata-rata & p \\
\hline sakit kepala & 20 & 48,000 & 0,000
\end{tabular}

Berdasarkan tabel diatas menunjukkan Hasil analisis data menggunakan Uji Wilcoxon menunjukkan nilai $\mathrm{P}=0.000$ lebih kecil dari $(\mathrm{P}<0,05)$ artinya $\mathrm{H} 1$ diterima $\mathrm{H} 0$ ditolak berarti ada pengaruh Pemberian teknik akupresur terhadap pengurangan nyeri sakit kepala pada ibu hamil trimester I di PMB Muarofah.

\section{Analisa Data}

Dari hasil penelitian diatas maka dapat dilakukan analisis dari data khusus yaitu pre-test dan post-test sehingga dapat ditentukan ada atau tidaknya impresi pemberian pemijatan pada titik bai hui, waiguan, fengchi, tay yang dan zanzu terhadap pengurangan cephalgia pada ibu hamil trimester pertama. Analisis data ini menggunakan Uji Wilcoxon. Didapatkan bahwa Nilai $P$ yang dihasilkan adalah 0,000 . Dengan nilai $p=0,000<\alpha=0,05$ $(\mathrm{P}<0,05)$ yang berarti bahwa $\mathrm{H} 1$ diterima, sehingga ada impresi pemberian pemijatan pada titik bai hui, waiguan, tay yang dan zanzu terhadap pengurangan cephalgia pada ibu hamil trimester pertama.

\section{PEMBAHASAN}

A. Sakit kepala pada ibu hamil sebelum dilakukan akupresur

Keluhan yang sering dialami oleh wanita hamil di trimester pertama yaitu cephalgia sehingga mengganggu aktifitasnya. Bahkan ada yang harus mendapatkan penanganan medis karena sakit kepala yang tidak tertahankan. Ibu hamil yang mengalami cephalgia dilarang meminum obat sembarangan karena efek sampingnya menganggu tumbuh kembang janin. (Mochtar, 2011). Cephalgia pada ibu hamil trimester I disebabkan adanya aliran darah ke tubuh meningkat pada saat ibu hamil akan merubah posisinya seperti pada saat berbaring akan duduk dan sebaliknya. Sakit kepala yang dirasakan . Faktor lain yang dapat menyebabkan cephalgia antara lain perubahan hormonal, hipoglikemi, dan perubahan emosional.(Sukarni, 2013). 


\section{B. Nyeri kepala pada ibu hamil sesudah akupresur}

Hasil penelitian menunjukkan bahwa distribusi responden berdasarkan nyeri sesudah intervensi sebagian besar mengalami nyeri ringan sebanyak 10 responden (50\%) dan sebagian kecil mengalami nyeri sedang sebanyak 1 responden (5.0\%). Jadi dapat disimpulkan dari 20 orang yang menderita sakikepala, setelah di akupresur rata rata mengalami penurunan yang dapat mengurangi sakit kepala pada ibu hamil TM 1.

Pada kenyataannya, mayoritas ibu hamil mengalami sakit kepala pada trimester pertama dan hal ini seringkali menjadi penyebab dari kecemasan dan ketidaknyamanan para ibu saat hamil. Beberapa terapi ditawarkan untuk mengatasi nyeri sakit kepala tersebut baik secara farmakologis (medis) maupun non farmakologi (non medis). Teknik penanganan nyeri non farmakologi antara lain relaksasi, imajinasi terbimbing, akupuntur, akupresur, psikoterapi (Sulistyoningrum, 2017).

Karena dengan melakukan akupresur dapat mengaktifkan peredaran energi vital qi sehingga dapat meningkatkan pengeluaran hormone endorphin dari dalam darah. Dengan meningkatnya hormone endorphin sehingga nyeri dapat terkontrol. Selain itu, dengan akupresur dapat menutup gerbang terhadap rangsang nyeri sehingga menurunkan intensitas cephalgia pada ibu hamil trimester pertama.

\section{Pengaruh Pemberian Akupresur Terhadap Pengurangan Nyeri Sakit Kepala}

Hasil analisis data menggunakan Uji wilcoxon menunjukkan $(\mathrm{P}<0,05)$ yang artinya $\mathrm{H} 1$ diterima sehingga ada impresi pemijatan pada titik bai hui, waiguan, fengchi, tay yang dan zanzu terhadap pengurangan cepahlgia pada ibu hamil trimester pertama PMB Muarofah A.Md Keb. Menurut peneliti sebelumnya menyatakan bahwa masalah kesehatan yang spesifik, termasuk nyeri cephalgia pada wanita hamil trimester pertama, terjadi ketika terdapat blockade arus energi sepanjang meridian tertentu dalam darah. (Nanur, 2014). Dengan melepaskan blockade tersebut, keserasian dan fungsi halus dapat dikembalikan. Akupresur dapat dijadikan salah satu alternatif merupakan salah satu alternatif yang dapat digunakan untuk meminimalkan rasa nyeri cephalgia pada ibu hamil trimester pertama. Prinsip dalam akupresur adalah dengan menghilangkan penghalang, merevitalisasi meridian, dan membantu memulihkan kesehatan dan akupresure dapat merangsang hormon endhoprin.

\section{KESIMPULAN DAN SARAN}

\section{KESIMPULAN}

1. Rata - rata nyeri cephalgia pada ibu hamil trimester pertama sebelum diberi perlakuan pemijatan adalah sebanyak 16 orang dengan nyeri cephalgia sedang, dan sebagian nyeri ringan sebanyak 4 orang

2. Nyeri cephalgia pada ibu hamil trimester pertama setelah perlakuan pemijatan adalah 9 orang mengalami tidak nyeri, 11 orang mengalami sakit kepala ringan.

3. Hasil analisis data menggunakan uji wilcoxon menunjukkan $(\mathrm{P}<0,05)$ ada impresi pemijatan pada titik bai hui, waiguan, fengcu, tay yang dan zanzu pengurangan nyeri cephalgia pada ibu hamil trimester pertama di PMB Muarofah A.Md Keb Surabaya.

\section{SARAN}

1. Bagi Tempat Penelitian

Dapat menjadikan hasil penelitian ini untuk reverensi dalam pengobatan komplementer untuk treatment dalam mengurangi nyeri cephalgia pada ibu hamil trimester pertama.

2. Bagi Tenaga kesehatan

Diharapkan dari penelitian ini bidan dapat menjadikan pengobatan komplementer sebagai salah satu treatment dalam mengurangi nyeri cephalgia yang dialami oleh ibu hamil trimester pertama di pelayanan kesehatan.

3. Bagi Peneliti Lain

Untuk peneliti selanjutnya untuk mengembangkan penelitian komplementer ini untuk mengurangi nyeri cephalgia yang dialami oleh ibu hamil trimester pertama dengan waktu lebih diperpanjang dalam melakukan penelitian dan responden yang lebih memadai.

DAFTAR PUSTAKA

Efriyanthi, S. (2015). PENGARUH TERAPI AKUPRESUR SANYINJIAO POINT TERHADAP INTENSITAS NYERI DISMENORE PRIMER PADA MAHASISWI SEMESTER VIII PROGRAM STUDI ILMU KEPERAWATAN. Coping: 
Community of Publishing in Nursing, 3(2).

Hasanah, O. (2014). Efektifitas Akupresur terhadap Dismenore pada Remaja Putri. Riau University,

Jayanti, N. D., \& Mayasari, S. I. PENGARUH PIJAT RELAKSASI TERHADAP PENURUNAN SAKIT KEPALA PADA IBU HAMIL TRIMESTER I.

Mochtar, R. (2011). Sinopsis Obstetri, Obstetri Fisiologi, Obstetri Patologis, Jilid I, Jakarta : EGC.

Nanur, F. N. (2014). PENGARUH PEMBERIAN TEKNIK AKUPRESUR TERHADAP NYERI PERSALINAN KALA I FASE AKTIF DI RSUD AMBARAWA 2013. Paper presented at the Prosiding Seminar Nasional \& Internasional.

Pravikasari, N. A. (2014). Perbedaan Senam Hamil dan Teknik Akupresur Terhadap Penurunan Nyeri Punggung Bawah pada Ibu Hamil Trimester III. Program Pascasarjana Undip,

Soeharyo, d. (2011). Epidemiologi Manajerial Teori dan Aplikasi. Semarang : Universitas Dipenegoro.

Sukarni, I. K. M. Z. (2013). Kehamilan, Persalinan, Nifas. Yogyakarta : Nuha Medika

ulistyoningrum, I. (2017). PENGARUH TEKNIK AKUPRESUR TERHADAP PENGURANGAN INTENSITAS NYERI KALA I PERSALINAN. 2-TRIK: TUNASTUNAS RISET KESEHATAN, 7(2), 143148.

Swarjana, I. K., S.K.M, M.Ph. (2015). Metodelogi Penelitian Kesehatan. Yogyakarta : Andi Offset. 